\title{
Correlation of breast cancer risk factors with HER-2/neu protein overexpression according to menopausal and estrogen receptor
} status

\author{
Nikos Tsakountakis*1, Elias Sanidas ${ }^{2}$, Efstathios Stathopoulos ${ }^{3}$, \\ Maria Kafousi ${ }^{3}$, Nektaria Anogiannaki ${ }^{4}$, Vasilis Georgoulias ${ }^{5}$ and \\ Dimitris D Tsiftsis ${ }^{2}$
}

Address: ${ }^{1}$ Dept of Family and Social Medicine, Heraklion Medical School, University of Crete, Greece, ${ }^{2}$ Dept of Surgical Oncology, Heraklion Medical School, University of Crete, Greece, ${ }^{3}$ Dept of Pathology, Heraklion Medical School, University of Crete, Greece, ${ }^{4}$ Dept of Biostatistics, Heraklion Medical School, University of Crete, Greece and ${ }^{5}$ Dept of Medical Oncology, Heraklion Medical School, University of $\geq$ Crete, Greece

Email: Nikos Tsakountakis* - drtsakou@yahoo.gr; Elias Sanidas - esanidas@med.uoc.gr; Efstathios Stathopoulos - stath@med.uoc.gr; Maria Kafousi - christom@uoc.gr; Nektaria Anogiannaki - nanog@mail.gr; Vasilis Georgoulias - georgoul@med.uoc.gr;

Dimitris D Tsiftsis - tsiftsis@med.uoc.gr

* Corresponding author

Published: 04 February 2005

BMC Women's Health 2005, 5:I doi:10.1186/1472-6874-5-1

This article is available from: http://www.biomedcentral.com/1472-6874/5/I

(C) 2005 Tsakountakis et al; licensee BioMed Central Ltd.

This is an Open Access article distributed under the terms of the Creative Commons Attribution License (http://creativecommons.org/licenses/by/2.0), which permits unrestricted use, distribution, and reproduction in any medium, provided the original work is properly cited.
Received: 16 October 2004

Accepted: 04 February 2005

\begin{abstract}
Background: Several researchers have claimed that classification of tumours on the basis of HER$2 /$ neu overexpression or amplification may define a subset of breast cancer in which the net effect of a risk factor could be rather more obvious and its impact on breast cancer development more clear. We decided to investigate, in a group of patients from a geographical area with a low incidence of breast cancer, whether HER-2/neu positive tumours are correlated with established or suspected risk factors for breast cancer and thus to identify distinct subgroups of high risk women.
\end{abstract}

Methods: This study analysed data from patients who attended the Breast Unit at the University Hospital of Heraklion, Crete, Greece between 1996 and 2002. 384 women with primary invasive breast cancer were compared with 566 screened women who were referred to the Unit and had not developed breast neoplasm by the time the data were analysed. Risk factor data were obtained from each subject by personal interviews using a structured questionnaire. The detection and scoring of the HER-2/neu protein, estrogen and progesterone receptor expression were performed using immunochemistry. Odds ratios and $95 \%$ confidence intervals were determined by chi-square test and logistic regression analysis. Case-case odds ratios were calculated in order to measure the risk heterogeneity between HER-2/neu+ and HER-2/neu-tumours. Separate analyses were performed for premenopausal and postmenopausal women and according to estrogen receptor status.

Results: In multivariate analysis without HER-2/neu stratification, an increased breast cancer risk was associated with only four of the factors examined: use of oral contraceptives (OR $=4.40$, 95\%C.I: I.46-I3.28), use of HRT (OR = 7.34, 95\%C.I: 2.03-26.53), an age at first full pregnancy more than 23 years (OR = I.9I, 95\%C.I: I.29-2.83) and body mass index more than $29 \mathrm{~kg} / \mathrm{m}^{2}(\mathrm{OR}$ $=3.13,95 \%$ C.I: $2.02-4.84$ ). Additionally, a history of abortion or miscarriage (OR $=0.56,95 \%$ C.I: 
0.38-0.82) was correlated with a decreased risk of breast cancer. In the case to case comparison only $\mathrm{BMI}>29 \mathrm{~kg} / \mathrm{m}^{2}$ revealed a relative connection that was stronger with positive than with negative HER-2/neu tumours (ratio of OR's $=2.23,95 \% \mathrm{C} . \mathrm{I}$ : I.20-4.I5, $\mathrm{p}=0.0 \mathrm{I}$ ) . This may indicate evidence of heterogeneity of a rather significant degree for this factor. In the ER negative group an age at first full pregnancy $>23$ years and a BMI $>29 \mathrm{~kg} / \mathrm{m}^{2}$ were associated with an increased risk in both HER-2/neu groups, but the association was significantly stronger for the latter factor in the positive HER-2/neu tumours (ratio of OR's = 2.46, 95\% Cl: 0.97-6.21).

Conclusions: Our study did not confirm that the established or putative hormonal breast cancer risk factors differ regarding their relations with HER-2/neu+ versus HER-2/neu-breast tumours, with the exception of increased BMI. Further innovative studies with larger sample sizes are needed to examine how the status of these potentially modifiable breast cancer risk factors interacts with biological markers such as HER-2/neu oncoprotein.

\section{Background}

The HER-2/neu oncogene, also known as c-erb-B2, c-neu or ERBB2, is located in chromosome 17q11.2-12, encoding an EGFR-family like glycoprotein [1]. Its amplification, which is strongly correlated with protein overexpression, occurs in about $15-43 \%$ of breast tumours [1-10].

The observation that morphologically similar neoplasmatic lesions of the breast can exhibit different biology has necessitated the identification of biological parameters that might improve risk assessment; the evaluation of HER-2/neu expression is a typical example [11]. Indeed, several studies have demonstrated that HER-2/neu amplification represents a prognostic and predictive marker; its expression is associated with early disease recurrence, relative resistance to chemo- and/or hormonotherapy and short survival $[2,10]$. In addition it has been shown that genetic alterations of the HER-2/neu oncogene represent early events involved in breast carcinogenesis and tumour initiation, while their presence is observed in all stages of malignant development from in situ carcinomas to metastatic lesions [12]. As a result, some researchers have maintained that HER-2/neu amplification and/or protein overexpression may also represent not only an important marker of prognosis but also a key indicator of the aetiological heterogeneity of breast carcinogenesis. [3,7-9].

On the other hand, the contribution of even well established breast cancer risk factors to the aetiology of carcinogenesis in the breast remains obscure, ill-defined and tenuous, mostly because of the existence of different pathways for the initiation and the evolution of a breast tumour [13]. In order to explain this incompatibility, several researchers have claimed that classification of tumours on the basis of HER-2/neu overexpression or amplification may define a subset of breast cancer in which the net effect of a risk factor could be rather more obvious and its impact on breast cancer development more clear $[3,7,8]$.
Thus, a close correlation of a risk factor with HER-2/neu overexpression could indicate either that a HER-2/neu alteration is the way that this risk factor evolves into the carcinogenesis or that there is a parallel interaction between them that leads to breast tumour initiation and development. Since the data in the literature supporting the above hypothesis are few and conflicting, we decided to investigate, in a group of patients from a geographical area with a low incidence of breast cancer, whether HER2/neu positive tumours are correlated with established or suspected risk factors for breast cancer and thus to identify distinct subgroups of high risk women.

\section{Methods}

This study analysed data derived from the database of the Breast Unit of the Department of Surgical Oncology at the University General Hospital of Heraklion on the island of Crete, Greece. The study considered all women who were consecutively diagnosed with primary, invasive breast cancer in our unit from 1996 to 2002. Subjects of other races, ethnicity, with residence outside Crete or diagnosed with DCIS or LCIS were excluded. Finally, 384 women, all originating from the island of Crete, were eligible for analysis.

An age-stratified random sample of 566 women was used as a control group, derived from the Breast Unit's database of screened patients who had not developed breast cancer after a median follow up period of 40 months (range 1292 months). Personal interviews were conducted with each woman during her first visit (both patients and controls) by a consultant or a senior resident. The interview followed a structured questionnaire, which did not change during the study period. Anthropometric measures were also made during the first visit.

Women were classified as postmenopausal if their menstrual cycles had ended naturally at least 12 months before the interview or from surgery or radiation therapy at any age. Those who reported not having menstrual 
cycles for the last 10 months were considered as perimenopausal and were combined with premenopausal women for the purpose of our analysis.

The following variables were analysed for all patients and controls: residence (rural/urban), age at interview ( $\leq 50$ and $>50$ years), age at menarche ( $\leq 12$ and $>12$ years old), age at first full birth ( $<23$ vs. $\geq 23$ years old), parity (nulliparous, 1 or 2 , and $>3$ ), lactation (yes/no), use of medications to suppress lactation (yes/no), abortions and miscarriages (yes/no), age at menopause for postmenopausal women $(\leq 50$ and $>50$ years old $)$, use of HRT for more than 2 months (yes/no), use of oral contraceptives for more than 2 months (yes/no), family history of breast cancer in a first degree relative (yes/no), history of benign breast disease (yes/no), obesity on the day of the interview $\left(\mathrm{BMI} \leq 29 \mathrm{~kg} / \mathrm{m}^{2}\right.$ vs. $\mathrm{BMI}>29 \mathrm{~kg} / \mathrm{m}^{2}$, median value for the study population) and radiation history of the chest (yes/ no).

\section{Immunohistochemical study}

For this study, tumour blocks were successfully retrieved in $378(98.4 \%)$ and in $377(98.17 \%)$ of the 384 interviewed cases for the immunohistochemical detection of HER-2/neu protein and hormone-receptor expression, respectively.

\section{Immunohistochemical detection and scoring of the HER-2I neu protein expression}

Immunohistochemistry with the monoclonal antibody CB11 (NCLCB11, Novocastra Laboratories, UK 12 8EW), at a dilution of $1 / 50$ with incubation period of $60 \mathrm{~min}$, was performed using the OPTIMAX automated system with the Super Sensitive Link-Label Detection System RTU Multilink AP/Fast Red, QA200OXE (purchased from Biogenex Laboratories, San Ramon CA 94583 USA), following antigen retrieval by microwave pre-treatment at 500 Watts for $3 \times 5 \mathrm{~min}$ in citrate buffer $(0.01 \mathrm{M}, \mathrm{pH} 6)$. Sections from breast cancer of known positivity were used as positive controls. Negative controls were processed by omitting the primary antibody and substituting nonimmune serum. Scoring was based on the criteria recommended by DAKO A/S for the HercepTest [14]. Only membrane staining pattern and intensity were scored using the $0-3+$ scale: scores of $0-1+$ were considered negative, score $2+$ was considered weak positive-need for FISH, and score $3+$ was considered (strongly) positive.

\section{Immunohistochemical detection and scoring of estrogen and progesterone receptors}

Three (3) $\mu$ m-thick sections taken on negatively-charged (SuperFrostPlus) slides were dewaxed in xylene, and rehydrated through graded alcohols. Following antigen retrieval by microwave pre-treatment at $500 \mathrm{~W}$ for $3 \times 5$ min in citrate buffer $(0.01 \mathrm{M}, \mathrm{pH} 6)$, estrogen receptor
(ERa) and progesterone receptor (PR) expression was detected by immunohistochemistry using the same automated system and detection kit as above, and primary monoclonal antibodies to ERa (DAKO M7047) and PR (Biogenex code \# MU 328-UC) at dilutions of $1 / 50$ and $1 /$ 20 , respectively, with incubation time $60^{\prime}$, at room temperature. Positive and negative controls were processed as above. Positive nuclei counting was performed at a final magnification of $400 \times$ (Teaching double-headed NICON, ECLIPSE E400 microscope, equipped with CFI 10X/22 oculars). After scanning at a final magnification of $100 \times$ for locating the areas with highest density of ER+ or PR+ carcinoma cell nuclei (hot spots), a 40X/¥/0.17 WD 0.65 objective lens was used for cell counting. All carcinoma cells in three hot spots per immunostained slide were evaluated by two pathologists working simultaneously, though independently, and the mean of the two independent counts was considered the final counting value for each field and hot spot. The ratio of the ER+ or PR+ carcinoma cell nuclei was recorded separately for each of the hot spots. The final immunoreactivity index (score) was calculated as the mean percentage of ER+ or PR+ carcinoma cell nuclei in the three hot spots. Specimens were interpreted as positive for ER or PR if at least $10 \%$ of the cells demonstrated nuclear staining of any intensity of reactivity, from $1+$ to $3+$. Staining intensity was graded as negative (0), weak $(1+)$, intermediate $(2+)$ or strong $(3+)$, and reported separately. A mean value of intensity was assigned for specimens in which the staining intensity varied from field to field, and/or from hot spot to hot spot.

\section{Statistical analysis}

Odds ratios (OR) and 95\% CI (confidence intervals), as approximators of relative risk, were calculated to measure the association of the groups of breast cancer and the risk factors, using the chi-square $\left(\chi^{2}\right)$ test. A $p$ value $<0.05$ was defined as significant. The potential association between breast cancers stratified by HER-2/neu status and well known predisposing factors was further investigated by using a stepwise logistic regression analysis (backward LR), testing the independent effect of breast cancer risk factors (independent variables) on breast cancer (dependent variable) for all women and also separately for premenopausal and postmenopausal females. In addition, we undertook further stratification with estrogen receptor status by using the same multivariate logistic regression model. These patient-controls odds ratios helped us to detect the pattern of heterogeneity and to explore plausible aetiological correlations between patient subgroups. Additionally, case-case odds ratios were calculated in order to measure the risk heterogeneity between HER-2/ $n e u+$ and HER-2/neu-tumours. It seems that the departure of the OR from unity can reveal the degree of heterogeneity between these subgroups [15]. 
Table I: Characteristics of the participants

\begin{tabular}{|c|c|c|c|c|}
\hline Factors & Cases $N=384 \mathrm{n}(\%)$ & Controls $N=566 \mathrm{n}(\%)$ & $\mathrm{OR}^{\prime}(95 \% \mathrm{Cl})$ & $\mathrm{OR}^{2}(95 \% \mathrm{Cl})$ \\
\hline \multicolumn{5}{|l|}{ Age at interview } \\
\hline$\leq 50$ years & $138(36)$ & $178(31)$ & 1.00 & \\
\hline$>50$ years & $246(64)$ & $388(69)$ & $0.82(0.62-1.08)$ & NS \\
\hline \multicolumn{5}{|l|}{ Area of residence } \\
\hline rural & $189(49)$ & $292(52)$ & 1.00 & \\
\hline urban & $195(51)$ & 274(48) & $0.91(0.70-1.18)$ & NS \\
\hline \multicolumn{5}{|l|}{ Menopausal status } \\
\hline Pre/perimenopausal & $134(35)$ & $170(30)$ & 1.00 & \\
\hline Postmenopausal & $250(65)$ & $396(70)$ & $0.80(0.60-1.06)$ & NS \\
\hline \multicolumn{5}{|l|}{ Age at menopause 3} \\
\hline$\leq 50$ years & |44(59) & $252(64)$ & 1.00 & \\
\hline$>50$ years & $102(4 I)$ & $140(36)$ & $1.28(0.92-1.77)$ & NS \\
\hline \multicolumn{5}{|l|}{ Age of menarche } \\
\hline$\leq 12$ years & $155(40)$ & $150(27)$ & $1.86(1.41-2.45)$ & \\
\hline$>12$ years & $229(60)$ & $412(73)$ & 1.00 & NS \\
\hline \multicolumn{5}{|l|}{ Use of oral contraceptives } \\
\hline no & $34 I(89)$ & $548(97)$ & 1.00 & 1.00 \\
\hline yes & $43(11)$ & $18(3)$ & $3.84(2.18-6.77)$ & $4.40(1.46-13.28)$ \\
\hline \multicolumn{5}{|l|}{ Use of $\mathrm{HRT}^{3}$} \\
\hline no & $231(92)$ & $393(99)$ & 1.00 & 1.00 \\
\hline yes & $19(8)$ & $3(1)$ & $10.78(3.15-36.8 I)$ & $7.34(2.03-26.53)$ \\
\hline \multicolumn{5}{|l|}{ First degree family history } \\
\hline 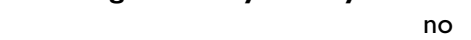 & $34 I(89)$ & $522(92)$ & 1.00 & \\
\hline yes & $43(11)$ & $44(8)$ & $1.5(0.96-2.33)$ & NS \\
\hline \multicolumn{5}{|l|}{ Age at first full pregnancy } \\
\hline$<23$ years & $106(35)$ & $239(50)$ & 1.00 & 1.00 \\
\hline$\geq 23$ years & $197(65)$ & $242(50)$ & $1.84(1.37-2.47)$ & $1.91(1.29-2.83)$ \\
\hline \multicolumn{5}{|l|}{ Parity } \\
\hline nulliparous & $79(20)$ & $78(14)$ & 1.00 & \\
\hline $1-2$ & $175(46)$ & $255(45)$ & $0.68(0.47-0.98)$ & NS \\
\hline 3 plus & $130(34)$ & $233(4 I)$ & $0.55(0.38-0.80)$ & NS \\
\hline \multicolumn{5}{|l|}{ Abortion or miscarriage } \\
\hline no & $183(57)$ & $247(50)$ & 1.00 & 1.00 \\
\hline yes & $138(43)$ & $248(50)$ & $0.75(0.57-0.99)$ & $0.56(0.38-0.82)$ \\
\hline \multicolumn{5}{|l|}{ Lactation } \\
\hline no & $67(22)$ & $84(17)$ & 1.00 & \\
\hline yes & $238(78)$ & $404(82)$ & $0.74(0.52-1.06)$ & NS \\
\hline \multicolumn{5}{|l|}{ Medication to suppress lactation } \\
\hline no & $273(90)$ & $438(90)$ & 1.00 & \\
\hline yes & $3 I(10)$ & $50(10)$ & $0.99(0.62-1.60)$ & NS \\
\hline \multicolumn{5}{|l|}{ Radiation to the chest } \\
\hline 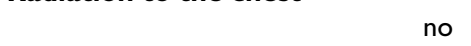 & $372(97)$ & $550(97)$ & 1.00 & \\
\hline yes & $12(3)$ & $16(3)$ & $1.11(0.52-2.37)$ & NS \\
\hline \multicolumn{5}{|l|}{ Body mass index } \\
\hline$\leq 29 \mathrm{~kg} / \mathrm{m}^{2}$ & $282(74)$ & $498(88)$ & 1.00 & 1.00 \\
\hline$>29 \mathrm{~kg} / \mathrm{m}^{2}$ & $97(26)$ & $68(12)$ & $2.52(1.79-3.55)$ & $3.13(2.03-4.84)$ \\
\hline \multicolumn{5}{|l|}{ Benign breast disease } \\
\hline 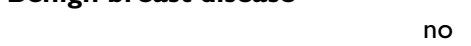 & $315(82)$ & $472(83)$ & 1.00 & \\
\hline yes & $69(18)$ & $94(17)$ & $1.10(0.78-1.55)$ & NS \\
\hline
\end{tabular}

'Adjusted for age. -2Adjusted for age, residence, menopausal status, menopausal age, menarche age, use of OC, use of HRT, first degree family history, age at first full pregnancy, parity, abortion, lactation, medication to suppress lactation, radiation to the chest, body mass index and benign breast disease. -3Postmenopausal women only.

NS: non significant multivariate OR. Bold types: statistically significant values. 
Table 2: Characteristics of the tumours of breast cancer patients'.

\begin{tabular}{|c|c|c|c|}
\hline Tumour characteristics & HER-2/neu + n = I45 (\%) & HER-2/neu- n = 233 (\%) & $p$ value \\
\hline Age at interview & & & 0.533 \\
\hline$\leq 50$ years & $55(40)$ & $81(60)$ & \\
\hline$>50$ years & $90(37)$ & $152(63)$ & \\
\hline Staging & & & 0.106 \\
\hline 1 & $30(45)$ & $36(55)$ & \\
\hline II & $76(35)$ & $143(65)$ & \\
\hline III & $20(34)$ & $39(66)$ & \\
\hline IV & $2(50)$ & $2(50)$ & \\
\hline Unknown & $17(57)$ & $13(43)$ & \\
\hline Tumour size & & & 0.161 \\
\hline TI & $55(44)$ & $71(56)$ & \\
\hline $\mathrm{T} 2$ & $65(35)$ & $121(65)$ & \\
\hline$>\mathrm{T} 3$ & $10(29)$ & $25(7 I)$ & \\
\hline Unknown & $15(48)$ & $16(52)$ & \\
\hline Menopausal status & & & 0.762 \\
\hline Pre/perimenopausal & $52(40)$ & $80(60)$ & \\
\hline Postmenopausal & $93(38)$ & $153(62)$ & \\
\hline Grading & & & 0.577 \\
\hline 1 & $7(33)$ & $14(67)$ & \\
\hline II & $64(36)$ & $113(64)$ & \\
\hline III & $60(43)$ & $80(57)$ & \\
\hline Unknown & $14(35)$ & $26(65)$ & \\
\hline Node Status & & & 0.119 \\
\hline Negative & $55(33)$ & $112(67)$ & \\
\hline Positive & $89(43)$ & $118(57)$ & \\
\hline Unknown & I (25) & $3(75)$ & \\
\hline Estrogen receptor status & & & 0.108 \\
\hline $\mathrm{Er}+$ & $60(33)$ & $120(67)$ & \\
\hline Er - & $85(43)$ & 112 (57) & \\
\hline Unknown & & i & \\
\hline Progesterone receptor status & & & 0.038 \\
\hline $\mathrm{Pr}+$ & $49(49)$ & $52(5 \mathrm{I})$ & \\
\hline Pr- & $96(35)$ & $180(65)$ & \\
\hline Unknown & & 1 & \\
\hline
\end{tabular}

IData for HER-2/neu status were missing for 6 of the 384 interviewed cases.

\section{Results}

Risk factor distributions in breast cancer patients and matched controls are presented in table 1 . The mean age at interview was 56.30 years. When all patients were compared with matched controls, and after adjustment for confounding factors, an increased breast cancer risk was associated with only four of the factors examined: use of oral contraceptives $(\mathrm{OR}=4.40,95 \%$ C.I: $1.46-13.28)$, use of HRT (OR = 7.34, 95\%C.I: 2.03-26.53), an age at first full pregnancy more than 23 years $(\mathrm{OR}=1.91,95 \% \mathrm{C} . \mathrm{I}$ : $1.29-2.83$ ) and body mass index more than $29 \mathrm{~kg} / \mathrm{m}^{2}$ (OR $=3.13$, 95\%C.I: 2.02-4.84). Additionally, a history of abortion or miscarriage ( $\mathrm{OR}=0.56,95 \%$ C.I: $0.38-0.82$ ) was correlated with a decreased risk of breast cancer. However, the number of oral contraceptive and HRT users was too small for reliable estimates of risk.
Tumour characteristics of breast cancer patients are shown in table 2 . Thirty eight percent (145/378) of the tumours showed HER-2/neu protein overexpression. HER-2/neu positive tumours were not related with menopausal state, age at interview, tumour size, grade and stage, nodal and estrogen receptor status, but there was a modest positive association between HER-2/neu and progesterone negative tumours.

\section{Menopausal status and estrogen receptor stratification}

Subgroups of women stratified by menopausal status were further analysed by a multivariate stepwise logistic regression model adjusted for the remaining variables (table 3 ). In the premenopausal group of women, an increased risk for HER-2/neu-tumours was observed for those women who reported an age at first full pregnancy $\geq 23$ years $(O R$ = 3.56, 95\%C.I: $1.70-7.46)$, a BMI $>29 \mathrm{~kg} / \mathrm{m}^{2}(O R=6.89$, 
Table 3: Multivariate analysis of risk factors and HER-2/neu overexpression according to menopausal status

\begin{tabular}{|c|c|c|c|}
\hline Risk Factors & $\begin{array}{l}\text { HER-2/neu+Cases/controls } \\
\text { OR }(95 \% \mathrm{Cl})\end{array}$ & $\begin{array}{l}\text { HER-2/neu-Cases/controls } \\
\text { OR }(95 \% \mathrm{Cl})\end{array}$ & $\begin{array}{l}\text { Ratio of the OR's Cases+/cases- } \\
\text { OR }(95 \% \mathrm{Cl})\end{array}$ \\
\hline \multicolumn{4}{|l|}{ PREMENOPAUSAL } \\
\hline Age at first full pregnancy $(\geq 23$ years $)$ & NS & $3.56(1.70-7.46)$ & NS \\
\hline Body mass index $\left(>29 \mathrm{~kg} / \mathrm{m}^{2}\right)$ & NS & $6.89(2.23-21.25)$ & NS \\
\hline Abortion or miscarriage(ever) & NS & $0.49(0.23-1.05)$ & $3.12(1.18-8.24)$ \\
\hline First degree family history(positive) & NS & $3.30(1.10-9.96)$ & $0.09(0.01-0.85)$ \\
\hline Use of oral contraceptives (ever) & NS & II.19(3.7-33.84) & $0.16(0.04-0.60)$ \\
\hline Age of menarche $(\leq 12$ years $)$ & $2.09(0.99-4.42)$ & NS & NS \\
\hline \multicolumn{4}{|l|}{ POSTMENOPAUSAL } \\
\hline Age at first full pregnancy $(\geq 23$ years $)$ & $2.19(1.23-3.91)$ & $1.66(1.03-2.66)$ & NS \\
\hline Body mass index $\left(>29 \mathrm{~kg} / \mathrm{m}^{2}\right)$ & $4.83(2.75-8.49)$ & $2.67(1.56-4.55)$ & $2.23(1.20-4.15)$ \\
\hline Abortion or miscarriage(ever) & $0.50(0.28-0.88)$ & $0.62(0.39-0.97)$ & NS \\
\hline First degree family history(positive) & NS & $2.23(1.08-4.63)$ & NS \\
\hline Use of estrogens (ever) & NS & $10.70(2.7 I-42.31)$ & $0.21(0.04-1.08)$ \\
\hline Use of oral contraceptives (ever) & NS & $6.47(1.89-22.16)$ & NS \\
\hline Age of menarche $(\leq 12$ years $)$ & NS & $1.72(1.07-2.75)$ & $0.54(0.28-1.04)$ \\
\hline \multicolumn{4}{|l|}{ ALL WOMEN } \\
\hline Age at first full pregnancy $(\geq 23$ years $)$ & $2.19(1.23-3.91)$ & $1.66(1.03-2.66)$ & NS \\
\hline Body mass index $\left(>29 \mathrm{~kg} / \mathrm{m}^{2}\right)$ & $4.83(2.75-8.49)$ & $2.67(1.56-4.55)$ & $2.23(1.20-4.15)$ \\
\hline Abortion or miscarriage(ever) & $0.50(0.28-0.88)$ & $0.62(0.39-0.97)$ & NS \\
\hline First degree family history(positive) & NS & $2.23(1.08-4.63)$ & NS \\
\hline Use of estrogens (ever) & NS & $10.70(2.71-42.31)$ & $0.21(0.04-1.08)$ \\
\hline Use of oral contraceptives (ever) & NS & $6.47(1.88-22.16)$ & NS \\
\hline Age of menarche $(\leq 12$ years $)$ & NS & $1.72(1.07-2.75)$ & $0.54(0.28-1.04)$ \\
\hline
\end{tabular}

Adjusted for age, residence, menopausal status, menopausal age, menarche age, use of OC, use of HRT, first degree family history, age at first full pregnancy, parity, abortion, lactation, medication to suppress lactation, radiation to the chest, body mass index and benign breast disease. NS: non significant.

95\%C.I: 2.23-21.25), first degree family history $(O R=$ $3.30,95 \%$ C.I:1.10-9.96) or use of oral contraceptives (OR $=11.19$, 95\%C.I 3.70-33.84), while an age at menarche less than 12 years was the only factor which slightly increased the risk in premenopausal HER-2/neu+ patients $(O R=2.09,95 \%$ C.I 0.99-4.42). Abortion played a less protective role $(p=0.068)$ for HER-2/neu-breast cancer in premenopausal than in postmenopausal women $(p=$ $0.038)$. However, the intercase comparison in the premenopausal subgroup showed an evidence of heterogeneity only for the HER-2/neu+ women who had ever had an abortion (ratio of the OR's $=3.12$, 95\%C.I:1.18-8.24), while use of oral contraceptives $(O R=0.16,95 \%$ C.I: $0.04-0.60, p=0.007)$ and a positive first degree family history $(O R=0.09,95 \%$ C.I: $0.01-0.85, p=0.035)$ showed a stronger association for HER-2/neu negative tumours.

The results of logistic regression were identical for all women and the postmenopausal groups of patients due to the large sample size. Patients with an age of menarche $\leq$ 12 years $(O R=1.72,95 \%$ C.I: $1.07-2.75)$, first degree family history $(O R=2.23$, 95\%C.I:1.08-4.63), use of HRT $(O R=10.70,95 \%$ C.I: $2.71-42.31)$ or $\mathrm{OC}(O R=6.47$,
95\%C.I:1.89-22.16) were at increased risk of developing HER-2/neu-breast cancer only, although the significance of the latter two factors was of little value due to the limited sample size. On the other hand, an age at first full pregnancy $\geq 23$ years and a BMI greater than $29 \mathrm{~kg} / \mathrm{m}^{2}$ increased breast cancer risk independently of HER-2/neu status, while a history of abortion decreased risk in the same way. In the case to case comparison only BMI $>29 \mathrm{~kg} /$ $\mathrm{m}^{2}$ revealed a relative stronger connection with positive than with negative HER-2/neu tumours (ratio of OR's = 2.23, 95\%C.I: $1.20-4.15, p=0.011$ ) and this may indicate an evidence of heterogeneity of a rather significant degree for this factor. The stronger association between an age at menarche $\leq 12$ years, use of HRT and negative as opposed to positive HER-2/neu status did not reach statistical significance ( $p=0.067$ and $\mathrm{p}=0.062$, respectively).

A different stratification pattern of our study's population is presented in table 4 . This multivariate model, further stratified by estrogen receptor status, confirmed the observed tight connections between HER-2/neu positivity and obesity already shown in the analysis so far. In more detail, although BMI $>29 \mathrm{~kg} / \mathrm{m}^{2}$ elevated risk for both ER 
Table 4: Multivariate analysis of risk factors and HER-2/neu overexpression according to ER' status.

\begin{tabular}{|c|c|c|c|}
\hline Risk Factors & $\begin{array}{l}\text { HER-2/neu+ Cases/controls } \\
\mathrm{OR}^{2}\left(95 \% \mathrm{Cl}^{3}\right)\end{array}$ & $\begin{array}{l}\text { HER-2/neu-Cases/controls } \\
\text { OR }(95 \% \mathrm{Cl})\end{array}$ & $\begin{array}{l}\text { Ratio of the OR's Cases+/cases- } \\
\text { OR }(95 \% \mathrm{Cl})\end{array}$ \\
\hline \multicolumn{4}{|l|}{ ER + cases } \\
\hline Body mass index $\left(>29 \mathrm{~kg} / \mathrm{m}^{2}\right)$ & $5.59(2.58-12.13)$ & $2.84(1.52-5.32)$ & NS \\
\hline Age at Ist pregnancy $(\geq 23$ years) & $2.09(0.97-4.53)$ & NS & NS \\
\hline First degree family history (positive) & NS & $2.18(0.92-5.14)$ & NS \\
\hline Abortion or miscarriage (ever) & $0.44(0.20-0.95)$ & $0.56(0.32-0.99)$ & NS \\
\hline \multicolumn{4}{|l|}{ ER - cases } \\
\hline Body mass index $\left(>29 \mathrm{~kg} / \mathrm{m}^{2}\right)$ & $5.33(2.59-10.94)$ & $2.41(1.15-5.04)$ & $2.46(0.97-6.21)$ \\
\hline Age at Ist pregnancy ( $\geq 23$ years) & $2.37(1.08-5.18)$ & $1.78(0.93-3.42)$ & NS \\
\hline First degree family history (positive) & NS & $2.72(1.05-7.07)$ & NS \\
\hline Age of menopause ( $>50$ years) & NS & $2.05(1.10-3.79)$ & NS \\
\hline Parity ( $1-2$ children) & NS & $2.38(1.21-4.67)$ & NS \\
\hline
\end{tabular}

Adjusted for age, residence, menopausal status, menopausal age, menarche age, use of OC, use of HRT, first degree family history, age at first full pregnancy, parity, abortion, lactation, medication to suppress lactation, radiation to the chest, body mass index and benign breast disease.

'ER: estrogen receptor. NS: non significant.

negative and positive tumours independently of HER-2/ neu status, the association was significantly stronger for positive HER-2/neu tumours in the ER negative group (ratio of OR's $=2.46,95 \%$ CI: 0.97-6.21). Additionally, in the same group an age at first full pregnancy $>23$ years revealed an increase of risk in both HER-2/neu groups, while first degree family history $(O R=2.72,95 \%$ C.I: $1.05-7.07, p=0.040)$, age at menopause $>50$ years $(O R=$ 2.05, 95\% C.I: $1.10-3.79, p=0.023$ ) and birth of $1-2$ children $(O R=2.38,95 \%$ C.I: $1.21-4.67, p=0.012)$ elevated risk for HER-2/neu negative tumours only. In the ER+ group of women the direct comparison between cases revealed no associations with any factor at all, while abortion showed a protective pattern against breast cancer which expressed estrogen receptors independently of HER-2/neu status.

\section{Discussion}

This epidemiological study, conducted in a low incidence Mediterranean population, [16] found that obesity was related with postmenopausal breast tumours that overexpress HER-2/neu oncoprotein. In fact, increased BMI elevated risk in both groups, but the comparison between HER-2/neu+ and HER-2/neu- tumours revealed a much stronger association with HER-2/neu+ breast cancers.

Very few studies have examined the possibility whether HER-2/neu status can help discriminate aetiologically distinct subgroups of breast cancer cases, and none of them has identified the effect of increased BMI with HER-2/neu positive tumours [3,5,7-9].

More specifically, in contrast with other investigators who have shown an elevated risk for HER-2/neu+ tumours with an early age at first full pregnancy, we found a strong elevated risk with a late age regardless of HER-2/neu protein expression [3]. Previous findings suggested an inverse relationship between abortion and HER-2/neu+ breast cancers, while we also found this inverse association but independently of HER-2/neu status [7]. Interestingly enough, abortion increased risk for HER-2/neu+ tumours only in the premenopausal group of women. Early contraceptive use has been positively associated with HER-2/ $n e u+$ breast cancer in two studies $[7,8]$, but our findings were different, revealing a positive association with HER$2 /$ neu negative tumours. However, because the number of oral contraceptive (and HRT) users in this study was small, this subgroup analysis was hindered by decreased power to detect associations of any magnitude. The slightly protective effect of parity found in the ageadjusted analysis was diminished after logistic regression and did not reveal any association with HER-2/neu status, in contrast with previous findings [7]. Breastfeeding was associated with increased risks for breast cancer in women with HER-2/neu positive tumours in one study while other investigators reported opposite results [3,9]. Although our study population showed a remarkable lactation incidence (almost $80 \%$ of the participants) we found no associations at all.

Our findings have similarities and differences with respect to previous reports that examined the associations of breast risk factors with HER-2/neu status. This inconsistency may reflect differences in study design, populations, and laboratory methodology. In this study we used immunochemistry (CB11 monoclonal antibody) to assess the HER-2/neu protein overexpression, which is highly correlated with gene amplification according to previous reports $[2,4]$. Also, the percentage of women with breast cancer and HER-2/neu protein overexpression 
found here was within the limits reported elsewhere $[3,5$ 9].

This lack of relationship between HER-2/neu protein overexpression and most of the hormone-related breast cancer risk factors does not completely agree with several hypotheses which have maintained that combined estrogen and HER-2/neu activation is closely involved in the same pathway in breast cancer carcinogenesis $[17,18]$.

The only hormone-related factor that was found to be related with HER-2/neu positive tumours in our study was high body mass index, which is an established risk factor that has an estrogen-mediated oncogenic effect on the mammary gland. More specifically, obesity is associated with higher breast cancer risk among postmenopausal women through greater lifetime exposure to higher levels of estrogens produced in adipose tissue and lower SHBG production $[19,20]$. Higher levels of circulating estrogens enhance the rate of cell division, and this hormoneinduced cellular proliferation can result in somatic mutations and finally lead to a malignant change. These alterations involve many genes, including those concerned with hormone metabolism and transport, DNA repair, as well as tumour suppressor genes and oncogenes such as the HER-2/neu gene $[18,21]$. According to some investigators, circulating estrogens can stimulate breast cancer cell proliferation, not only through hormone receptors, but also through the HER-2/neu receptor, and so promote carcinogenesis through common means $[4,17,18]$.

Numerous epidemiological and experimental studies have shown the strong relationship between HER-2/neupositivity and lack of hormone receptor expression in breast tumours $[2,10,18,22]$. In our study, HER-2/neu positive tumours were weakly related with the absence of estrogen receptors, although this was not statistically significant (see table 2). Because different ER status can result in different correlations between risk factors and HER-2/ $n e u+$ breast cancer, it is always important to examine these interactions under ER stratification [8]. Since antiestrogens can lower HER-2/neu levels in ER negative tumours, it is possible that an excess of estrogens can stimulate HER-2/neu in these tumours $[8,18]$. This mechanism could explain the stronger association between obesity (a situation with an overload of estrogens as mentioned above) and HER-2/neu-positivity among ER negative patients that was found in the present study (see table 5).

The interview was conducted during the subjects' first visit to the unit and before clinical examination or any other intervention took place. This constitutes an advantage, because there was no chance that the subjects (both cases and controls) would be influenced by the diagnosis and might therefore falsely inflate the relative risk. Thus, the likelihood of recall bias is not high, improving the comparability of several covariates in both groups, and the selection bias is lessened since all subjects had taken the same route through the Breast Unit's standard routine procedures.

Since each case group was compared with the same control group, any selection bias would be expected to have a similar effect on the estimates in the tumour subgroups. Thus, it is extremely unlikely that recall bias issues would apply only to those cases in a specific HER-2/neu status subgroup. Some caution regarding our findings is related to the size of the study group. In the analyses stratified by HER-2/neu and menopausal or ER status numbers are quite small and for some risk estimates the confidence intervals are wide and the estimates of risk unstable.

\section{Conclusions}

In conclusion, our study did not confirm that the established or putative hormonal breast cancer risk factors differ regarding their relations with HER-2/neu+ versus HER2/neu-breast tumours, with the exception of increased BMI. Further innovative studies with larger sample sizes are needed to examine how the status of these potentially modifiable breast cancer risk factors interacts with biological markers such as HER-2/neu oncoprotein. Their findings will provide us with greater insight into breast cancer aetiology and will help us identify any association that would help discriminate subgroups of women at higher risk.

\section{Abbreviations}

EGFR: epidermal growth factor receptor, HRT: hormone

replacement therapy, BMI: body mass index, SHBG: sex hormone-binding protein, ER: estrogen receptor, PR: progesterone receptor, OC: oral contraceptives.

\section{Competing interests}

The author(s) declare that they have no competing interests.

\section{Authors' contributions}

NT conceived the study, participated in its design and drafted the manuscript.

ES participated in the design of the study, assisted in writing and reviewed the final article.

EfS and KM scheduled and performed the laboratory analysis.

NA performed the statistical analyses. 
VG and DDT participated in the design and coordination of the study and reviewed the final article.

All authors have read, discussed and approved the manuscript.

\section{Acknowledgements}

None.

\section{References}

I. Callahan R: Genetic alterations in primary breast cancer. Breast Cancer Res Treat 1989, 13:191-203.

2. Ciocca DR, Fujimura FK, Tandon AK, Clark GM, Mark C, Lee-Chen GJ., Pouns GW, Vendely P, Owens MA, Pandian MR: Correlation of HER-2/neu amplification with expression and with other prognostic factors in 1103 breast cancers. J Natl Cancer Inst 1992, 84: I 279-1282.

3. Treurniet HF, Rookus MA, Peterse HL, Hart AA, van Leeuwen FE: Differences in breast cancer risk factors to neu (c-erbB2) protein overexpression of the breast tumor. Cancer Res 1992, 52:2344-2345.

4. Isola JL, Chu S, DeVries K, Matsumura K, Chew K, Ljung BM, Waldman FM: Genetic Alterations in ERBB2-amplified Breast Carcinomas. Clin Cancer Res 1999, 5:4I40-4|45.

5. Rosen PP, Lesser ML, Arroyo CD, Cranor M, Borgen P, Norton L: Immunohistochemical detection of HER2/neu in patients with auxiliary lymph node negative breast carcinoma. Cancer 1995, 75:1320-1326.

6. De Potter CR: The neu-oncogene: more than a prognostic indicator? Hum Pathol 1994, 25: $1264-1268$.

7. Olsson H, Borg A, Ferno M, Ranstam J, Sirgurdsson H: Her-2/neu and INT2 proto-oncogene amplification in malignant breast tumors in relation to reproductive factors and exposure to exogenous hormones. J Natl Cancer Inst 199|, 83: | 483- | 487.

8. Gammon MD, Hibshoosh H, Terry MB, Bose S, Schoenberg JB, Brinton LA, Bernstein JL, Thompson WD: Oral contraceptive use and other risk factors in relation to HER-2/neu overexpression in breast cancer among young women. Cancer Epidemiol Biomarkers Prev 1999, 8:413-419.

9. Huang WY, Newman B, Millikan RC, Conway K, Hulka BS, Schell MJ, Liu ET: Risk of breast cancer according to the status of HER$2 /$ neu oncogene amplification. Cancer Epidemiol Biomarkers Prev 2000, 9:65-71.

10. Jukkola A, Bloigu R, Soini Y, Savolainen ER, Holli K, Blanco G: c-erbB2 Positivity is a factor for poor prognosis in breast cancer and poor response to hormonal or chemotherapy treatment in advanced disease. Eur J Cancer 200I, 37:347-354.

II. Murphy LC, Watson P: Steroid receptors in human breast tumorigenesis and breast cancer progression. Biomed Pharmacother 2002, 56:65-77.

12. Liu ET, Thor A, He M, Barcos M, Ljung BM, Benz C: The HER2 (cerbB-2) oncogene is frequently amplified in in situ carcinomas of the breast. Oncogene 1992, 5:1027-1032.

13. Liu ET: Oncogenes, breast cancer, and chemoprevention. / Cell Biochem 1993, I7G:16I-166.

14. DAKO A/S, Glostrup DK-2600 Denmark, code \# K 52042.

15. Begg CB, Zhang ZF: Statistical analysis of molecular epidemiology studies employing case-series. Cancer Epidemiol Biomarkers Prev 1994, 3:173-175.

16. Vlachonikolis IGt, Aletra TJ, Georgoulias V: Incidence of breast cancer on Crete, 1994-1995. Eur J Cancer 2002, 38:574-577.

17. Matsuda S, Kadowaki $\mathrm{Y}$, Ichino M, Akiyama T, Toyoshima K, Yamamoto T: I 7b-Estradiol mimics ligand activity of the c-erb B2 proto-oncogene product. Proc Natl Acad Sci 1993, 90:10803-10807.

18. De Bortoli M, Maggiora P, Capello D, Antoniotti S, Saviozzi S, Sapei ML, Dati C: Hormonal control of growth factor receptor expression. Ann N Y Acad Sci 1996, 784:336-348.

19. Cauley JA, Gutai JP, Kuller LH, LeDonne D, Powell JG: The epidemiology of serum sex hormones in postmenopausal women. Am J Epidem I 29(6): | |20- | |3|.

20. Bernstein L: Epidemiology of endocrine-related risk factors for breast cancer. J Mammary Gland Biol Neoplasia 2002, I:3-I5.
21. Lippman ME, Dickson RB: Mitogenic regulation of normal and malignant breast epithelium. Yale J Biol Med 1989, 62:459-480.

22. Konecny G, Pauletti G, Pegram M, Untch M, Dandekar S, Aguilar Z, Wilson C, Rong HM, Bauerfeind I, Felber M, Wang HJ, Beryt M, Seshadri R, Hepp H, Slamon DJ: Quantitative association between her-2/neu and steroid hormone receptors in hormone receptor-positive primary breast cancer. J Natl Ca Inst 2003, 95(2): $142-153$.

\section{Pre-publication history}

The pre-publication history for this paper can be accessed here:

\section{http://www.biomedcentral.com/1472-6874/5/1/prepub}

Publish with Biomed Central and every scientist can read your work free of charge

"BioMed Central will be the most significant development for disseminating the results of biomedical research in our lifetime. "

Sir Paul Nurse, Cancer Research UK

Your research papers will be:

- available free of charge to the entire biomedical community

- peer reviewed and published immediately upon acceptance

- cited in PubMed and archived on PubMed Central

- yours - you keep the copyright

Submit your manuscript here:

http://www.biomedcentral.com/info/publishing_adv.asp
BioMedcentral 